\title{
Título da página eletrónica: Cartas do Cárcere
}

URL: https://medium.com/cartas-do-carcere

\section{Elisa Scaraggi}

\section{(2) OpenEdition \\ Journals}

Edição electrónica

URL: http://journals.openedition.org/rccs/10037

DOI: $10.4000 /$ rccs. 10037

ISSN: 2182-7435

\section{Editora}

Centro de Estudos Sociais da Universidade de Coimbra

Edição impressa

Data de publição: 1 dezembro 2019

Paginação: 215-216

ISSN: 0254-1106

Refêrencia eletrónica

Elisa Scaraggi, «Título da página eletrónica: Cartas do Cárcere », Revista Crítica de Ciências Sociais [Online], 120 | 2019, posto online no dia 12 dezembro 2019, consultado o 25 setembro 2020. URL : http://journals.openedition.org/rccs/10037 ; DOI : https://doi.org/10.4000/rccs.10037 


\section{Espaço Virtual}

\section{Título da página eletrónica: Cartas do Cárcere* URL: https://medium.com/cartas-do-carcere}

O Brasil tem a terceira maior população carcerária do mundo e um sistema prisional obsoleto, que, há alguns anos, o então Ministro da Justiça comparou a "masmorras medievais". ${ }^{1}$ É um sistema que se avoluma cada vez mais, mas que está sempre à beira da crise e do colapso, marcado pela superlotação endêmica, a falta de recursos básicos, a violência e os abusos cotidianos. Nos últimos anos, assistiu-se a uma sucessão de vários motins que resultaram na morte violenta de dezenas de presos e que demonstraram a insustentabilidade do sistema, além de apontar para a necessidade urgente de encontrar soluções alternativas às políticas de encarceramento em massa. Porém, no país onde o atual Presidente da República se faz promotor do slogan "bandido bom é bandido morto" - e no qual grande parte da sociedade concorda com ele,$-^{2}$ os direitos dos presos são raramente tomados em consideração. Caracterizados simplesmente enquanto bandidos, mulheres e homens encarcerados têm suas experiências silenciadas. À pena de privação da liberdade juntam-se o estigma, o esquecimento, a morte social.

O projeto Cartas do Cárcere, uma parceria entre o Programa das Nações Unidas para o Desenvolvimento (PNUD) e a Pontifícia Universidade Católica do Rio de Janeiro (PUC-Rio), visou construir uma outra narrativa sobre a realidade prisional, recuperando as palavras de mulheres e homens encarcerados e focando nas suas experiências subjetivas. Uma das finalidades do projeto foi desconstruir os estereótipos que estigmatizam as pessoas encarceradas para lhes devolver a sua humanidade, passando a considerá-las como cidadãs, detentoras de direitos.

Em vez de analisar a correspondência pessoal dos presos, o projeto focou nas solicitações e denúncias que estes enviaram às autoridades responsáveis pela sua custódia, supostos garantes dos seus direitos. Porém, a comunicação não é fácil, nem imediata: como é possível averiguar no site, cada carta - quando não é censurada e consegue sair do presídio - passa por um processo longo e demorado, que poucas vezes garante que os pedidos formulados sejam atendidos. Partindo do princípio que a falha na comunicação é mais uma violação dos direitos das pessoas encarceradas, a equipe por trás do projeto recolheu e examinou mais de 8000 cartas enviadas à Ouvidoria Nacional dos Serviços Penais (ONSP), sistematizando os pedidos nelas formulados. A maioria das cartas foi enviada por homens e mulheres encarcerados, mas há também cartas enviadas por terceiros, nomeadamente mães e esposas. Este último aspeto se encaixou numa dimensão mais ampla do projeto,

\footnotetext{
* Este texto foi desenvolvido com o apoio concedido pela Fundação para a Ciência e a Tecnologia no âmbito da Bolsa de Doutoramento com a referência PD/BD/113727/2015.

${ }^{1}$ Ver https://veja.abril.com.br/brasil/em-decisao-historica-stf-intervem-no-sistema-carcerario/. Consultado a 09.09.2019.

2 Ver https://blogs.oglobo.globo.com/lauro-jardim/post/ibope-50-dos-brasileiros-acham-quebandido-bom-e-bandido-morto.html. Consultado a 09.09.2019.
} 
que prestou particular atenção às questões de gêneros levantadas pelo encarceramento, dedicando espaço a mulheres cis e trans afetadas pelo sistema prisional brasileiro. $\mathrm{Na}$ página eletrônica do projeto é possível acessar gratuitamente o livro Vozes do cárcere: ecos da resistência política que, além de recolher ensaios científicos e reflexões elaboradas a partir do material analisado sob vários aspetos e cortes metodológicos, inclui uma amostra significativa das cartas estudadas.

Além do mais, durante o período de atuação do projeto (2017-2018), seja na página eletrônica ou através das redes sociais, a equipe disponibilizou semanalmente um conjunto de materiais - incluindo artigos de jornais, entrevistas, gráficos e vídeos - com o intuito de criar uma discussão pública sobre o assunto e de apagar a distância que separa as pessoas encarceradas da assim chamada sociedade civil.
Embora o projeto tenha acabado em 2018 com a publicação do livro já citado, e embora a apresentação semanal de notícias não esteja atualizada há algum tempo, ainda é possível encontrar nesta página material de grande interesse. Como afirmou numa entrevista o coordenador da pesquisa do projeto, Felipe Freiras, este material é uma ferramenta pensada tanto para pesquisadores como para grupos que atuam em defesa dos direitos das pessoas privadas de liberdade, para que possam argumentar melhor as denúncias contra o sistema prisional e, ao mesmo tempo, construir uma narrativa que visibilize as experiências pessoais de sujeitos encarcerados. Porque embora ter a própria história contada não resolva o problema, possibilita uma forma muito elementar de resistência e empoderamento. ${ }^{3}$

Elisa Scaraggi

\section{Título da página eletrónica: Critical Resistance* URL: http://criticalresistance.org/}

Critical Resistance é um movimento de ativismo abolicionista estado-unidense comprometido com o combate ao complexo industrial-prisional e com a disseminação do abolicionismo anticarcerário a nível internacional. A página da organização apresenta a sua missão, a sua história e a sua visão, bem como informação atualizada relativamente à sua intervenção no contexto estado-unidense, que se divide entre quatro grandes núcleos urbanos: Los Angeles, Nova Iorque, Oakland e Portland. O site apela, no entanto, a um horizonte mais lato, tratando-se efetivamente de uma oportunidade de introdução ao vocabulário concetual abolicionista corrente e de acesso a múltiplos recursos em torno do abolicionismo anticarcerário, incluindo toolkits, materiais audiovisuais, testemunhos e documentação. A página apresenta uma diversidade notória de conteúdos e ferramentas, da qual aqui se destaca o projeto The Abolitionist, um jornal abolicionista criado em 2005, redigido em inglês e espanhol, e que circula gratuitamente em contextos de encarceramento e detenção nos Estados Unidos.

Daniel Lourenço

\footnotetext{
${ }^{3}$ Consultado a 09.09.2019, em https://www.youtube.com/watch?v=rECeYrMxOmo.

* Este texto foi desenvolvido com o apoio concedido pela Fundação para a Ciência e a Tecnologia no âmbito da Bolsa de Doutoramento com a referência PD/BD/113725/2015.
} 


\section{Título da página eletrónica: Journal of Prisoners on Prisons* URL: http://www.jpp.org/}

Journal of Prisoners on Prisons é uma revista canadiana, incorporada na tradição da publicação penal e focada na produção crítica por parte de prisioneiros/as e ex-prisioneiros/as. Com um acordo especial de distribuição com a Universidade de Ottawa, a revista parte de um etos abolicionista, ciente da implicação da produção científica em dinâmicas institucionais, económicas e editoriais que circunscrevem as condições de conhecimento e comunicabilidade do cárcere enquanto espaço de vida e espaço de articulação. Em termos de design e formatação, a página releva tendências comuns na construção e organização de páginas especificamente dedicadas a revistas académicas. O site explicita os critérios de edição da revista, métodos de arbitragem científica e meios de circulação, bem como a sua história organizacional - e a sua particular ênfase em públicos encarcerados. A página providencia ainda acesso gratuito aos volumes 1 a 26, publicados entre 1988 e 2017, disponíveis para download em formato PDF, e uma secção de particular relevo dedicada à exposição da arte utilizada na capa de cada edição e focada na sua criação por prisioneiros/as ou ex-prisioneiros/as.

Daniel Lourenço

\section{Elisa Scaraggi}

Centro de Estudos Comparatistas (CEC), Faculdade de Letras da Universidade de Lisboa (FLUL) I

Projecto CILM - City and Insecurity in Literature and Media, CEC-FLUL

Alameda da Universidade, 1600-214 Lisboa, Portugal

Contacto: elisascaraggi@gmail.com

ORCID: https://orcid.org/0000-0002-1411-8929

\section{Daniel Lourenço}

Centro de Estudos Comparatistas (CEC), Faculdade de Letras da Universidade de Lisboa (FLUL) I

Projecto CILM - City and Insecurity in Literature and Media, CEC-FLUL

Alameda da Universidade, 1600-214 Lisboa, Portugal

Contacto: d.h.lour@gmail.com

ORCID: https://orcid.org/0000-0003-3359-0820

* Este texto foi desenvolvido com o apoio concedido pela Fundação para a Ciência e a Tecnologia no âmbito da Bolsa de Doutoramento com a referência PD/BD/113725/2015. 
